\title{
Yadanzigan, a quassinoid glucoside, attenuates NLRP3 inflammasome activation to prevent LPS-induced acute lung injury
}

\author{
Yushun Cui ${ }^{1}$, Renyikun Yuan ${ }^{1}$, Quan Wen ${ }^{1}$, Yanzhi Zhan ${ }^{1}$, Wentong Zhao ${ }^{1}$, Shan Han ${ }^{2}$, Jia \\ $\mathrm{He}^{2}$, Qinqin Wang ${ }^{2}$, Xinxing $\mathrm{Li}^{2}$, Shi-lin Yang ${ }^{3}$, Hongwei Gao ${ }^{4}$, and Yu-lin Feng ${ }^{1}$ \\ ${ }^{1}$ Jiang Xi University of Traditional Chinese Medicine \\ ${ }^{2}$ GuangXi University of Chinese Medicine \\ ${ }^{3}$ Soochow University \\ ${ }^{4}$ University of Macau
}

May 5, 2020

\begin{abstract}
BACKGROUND AND PURPOSE Acute lung injury (ALI) is a challenging clinical syndrome that manifests as an acute inflammatory response. The NLRP3 inflammasome is involved in the development of ALI. Yadanzigan (YDZG) is isolated from Brucea javanica (Linn.) Merr (Simaroubaceae) (Yadanzi), an anti-inflammatory herb widely used in traditional Chinese medicine. However, the anti-inflammatory effect and mechanism of YDZG on ALI have not been reported. $\neg$ EXPERIMENTAL APPROACH The in vitro anti-inflammatory effect and mechanism of YDZG were investigated through ELISA, qRT-PCR, Western blotting, and immunoprecipitation assay. ALI model was established by non-invasive intratracheal instillation of LPS into lung of mice. The therapeutic effect of YDZG on ALI was assessed by changes in histopathological and pro-inflammatory markers. The underlying mechanisms were investigated by Western blotting on lung tissue. KEY RESULTS YDZG specifically inhibits NLRP3 inflammasome activation. In cultured macrophages, YDZG attenuated the NF- $x$ B pathway and mitochondrial reactive oxygen species production and enhanced TRIM31 expression to inhibit NLRP3 inflammasome activation. YDZG also ameliorated LPS-induced acute lung injury in mice by inhibiting the expression of NLRP3. CONCLUSIONS AND IMPLICATIONS This study uncovers the underlying mechanism and the anti-inflammatory activity of YDZG in ALI, suggesting that NLRP3 inflammasome may be an effective target of the treatment with ALI.
\end{abstract}

Yadanzigan, a quassinoid glucoside, attenuates NLRP3 inflammasome activation to prevent LPS-induced acute lung injury

Yushun $\mathrm{Cui}^{1,2}$, Renyikun Yuan ${ }^{1,3}$, Quan Wen ${ }^{1,3}$,Yanzhi Zhan ${ }^{1,3}$, Wentong Zhao ${ }^{1,3}$, Shan $\mathrm{Han}^{2,4}, \mathrm{Jia} \mathrm{He}^{2,4}$, Qinqin Wang ${ }^{2,4}$, Xinxing $\mathrm{Li}^{2,4}$, Shilin Yang ${ }^{2,4}$, Hongwei Gao ${ }^{2,4^{*}}$, Yu-Lin Feng ${ }^{1,3^{*}}$

${ }^{1}$ Jiangxi University of Traditional Chinese Medicine, Nanchang, China

${ }^{2}$ College of Pharmacy, Guangxi University of Chinese Medicine, Nanning, China;

${ }^{3}$ State Key Laboratory of Innovative Drug and Efficient Energy-Saving Pharmaceutical Equipment, Nanchang, China

${ }^{4}$ Guangxi Engineering Technology Research Center of Advantage Chinese Patent Drug and Ethnic Drug Development, Nanning, China

Yushun Cui and Renyikun Yuan contributed equally to this work.

Running title: Yadanzigan prevents LPS-induced acute lung injury 
*Address for correspondence:

Dr. Hongwei Gao, College of Pharmacy, Guangxi University of Chinese Medicine, Nanning, China, Tel: +8613878876311, Fax: +86-771-4953513, Email: gaohongwei06@126.com

Dr. Yu-Lin Feng, State Key Laboratory of Innovative Drug and Efficient Energy-Saving Pharmaceutical Equipment, Jiangxi University of Traditional Chinese Medicine, Nanchang, China,Tel:+86-791-87119632, Fax:+86-791-87119620, Email: fengyulin2003@126.com

Word count (excluding figure legends and references): 4441

\section{Acknowledgements}

This study was supported by the National Key R\&D Program of China (2019YFC1712300) and the National Natural Science Foundation of China $(81803807,81860684)$.

Conflict of interestThe authors declare no conflicts of interest.

Declaration of transparency and scientific rigourThis declaration acknowledges that this paper adheres to the principles for transparent reporting and scientific rigour of preclinical research recommended by funding agencies, publishers and other organizations engaged with supporting research.

\section{Author contributions}

H.G. and Y. L. F. designed the experiments; Y. C., R. Y., Y. Z., Q.W., S.H., W. Z., J.H., Q. W. and X. L. performed the experiments; Y. C. composed the draft; R. Y., H. G., S. Y. and Y. L. F. revised the manuscript.

\section{List of abbreviations}

ALI, acute lung injury; ARDS, acute respiratory distress syndrome; NLRP3, nod-like receptor 3; IL-1 $\beta$, interleukin $1 \beta$. PAMPs, pathogen associated molecular patterns; DAMPs, damage associated molecular patterns; LPS, lipopolysaccharide; ATP, adenosine triphosphate; IKK, I $\varkappa$ B kinase; iNOS, inducible NOS; TLR, toll-like receptor; BALF, bronchoalveolar lavage fluid; MPO, myeloperoxidase; RT-qPCR, real-time quantitative reverse transcription PCR

\section{Abstract \\ BACKGROUND AND PURPOSE}

Acute lung injury (ALI) is a challenging clinical syndrome that manifests as an acute inflammatory response. The NLRP3 inflammasome is involved in the development of ALI. Yadanzigan (YDZG) is isolated fromBrucea javanica (Linn.) Merr (Simaroubaceae) (Yadanzi), an anti-inflammatory herb widely used in traditional Chinese medicine. However, the anti-inflammatory effect and mechanism of YDZG on ALI have not been reported.

\section{EXPERIMENTAL APPROACH}

The in vitro anti-inflammatory effect and mechanism of YDZG were investigated through ELISA, qRT-PCR, Western blotting, and immunoprecipitation assay. ALI model was established by non-invasive intratracheal instillation of LPS into lung of mice. The therapeutic effect of YDZG on ALI was assessed by changes in histopathological and pro-inflammatory markers. The underlying mechanisms were investigated by Western blotting on lung tissue.

\section{KEY RESULTS}

YDZG specifically inhibits NLRP3 inflammasome activation. In cultured macrophages, YDZG attenuated the NF- $\varkappa$ B pathway and mitochondrial reactive oxygen species production and enhanced TRIM31 expression to inhibit NLRP3 inflammasome activation. YDZG also ameliorated LPS-induced acute lung injury in mice by inhibiting the expression of NLRP3. 
CONCLUSIONS AND IMPLICATIONSThis study uncovers the underlying mechanism and the antiinflammatory activity of YDZG in ALI, suggesting that NLRP3 inflammasome may be an effective target of the treatment with ALI.

Keywords: Yadanzigan; NLRP3 inflammasome; NF-xB; TRIM31; Acute lung injury

\section{Introduction}

Acute lung injury (ALI) and its more severe form, acute respiratory distress syndrome (ARDS), are common and devastating clinical disorders with high morbidity and mortality rates (Rubenfeld et al., 2005; Ware \& Matthay, 2000). ALI is characterized by intense inflammation of lung tissue with neutrophil accumulation, interstitial edema, disruption of endothelial and epithelial integrity, and leakage of protein into the alveolar space. These symptoms can lead to pulmonary edema, intrapulmonary hemorrhage, and severely impaired pulmonary gas exchange (Mohan et al., 2008; Schell-Chaple et al., 2015). Many conditions can lead to ALI, including sepsis, pancreatitis, multiple trauma, pneumonia, aspiration of gastric contents, pulmonary contusion, and inhalation of injurious gases (Standiford \& Ward, 2016). Despite the great progress that has been made in understanding the pathophysiology of ALI/ARDS, limited therapeutic strategies have been effective for treating ARDS patients. Moreover, no Food and Drug Administration-approved ALI/ARDS treatment exists (Johnson \& Matthay, 2010). Therefore, to research and develop effective drugs to treat ALI/ARDS is imperative.

Previous studies indicated that NLRP3 inflammasome is always involved in ALI (Dolinay et al., 2012). NLRP3 inflammasome is a multi-protein complex which comprises the innate immune sensor NLRP3, ASC, and caspase-1, which serves as a platform for caspase-1 activation (Jo et al., 2015). The inflammasome promotes the pro-IL- $1 \beta$ and pro-IL-18 cleavage to produce mature and functional IL- $1 \beta$ and IL-18, respectively. Activation of the NLRP3 inflammasome in macrophages requires two steps: priming and activation (Sutterwala et al., 2014; Yang et al., 2019). The priming step (signal 1) is provided by inflammatory stimuli such as TLR4 agonists, which induce NF- $\chi B$-mediated NLRP3 and pro-IL-1 $\beta$ expression. The activation step (signal 2) is triggered by PAMPs and DAMPs, which promotes NLRP3 inflammasome assembly and caspase-1-mediated IL-1 $\beta$ and IL-18 secretion (Tschopp \& Schroder, 2010). The level of NLRP3 expression is considered as a limiting step in inflammasome activation (Song et al., 2016). In resting macrophages, the concentration of NLRP3 protein is relatively low, therefore NLRP3 inflammasome assembly is rarely induced. When the NF- $x \mathrm{~B}$ pathway is activated, $\mathrm{NF}-x \mathrm{~B} / \mathrm{p} 65$ is released and translocated from the cytoplasm to the nucleus (Gao et al., 2017), leading to NLRP3 protein expression (He et al., 2016) and initiating the transcription of pro-inflammatory mediators such as TNF- $\alpha$, iNOS, COX-2, IL-1 $\beta$, and IL-6. To suppress the NF- $x$ B pathway causes inhibition of NLRP3 inflammasome activation, eventually blocking the secretion of these cytokines. In addition, TRIM31 is a member of the TRIM protein family (Liu et al., 2017), which directly binds to NLRP3 and promotes K48-linked ubiquitination, leading to NLRP3 proteasomal degradation and inhibition (Song et al., 2016). This feature makes TRIM31 a good potential target for the inhibition of NLRP3 inflammasome activation (Song et al., 2016). Therefore, to enhance TRIM31 expression leads to inhibition of NLRP3 inflammasome is an important strategy for anti-inflammatory drug discovery.

Yadanzigan (YDZG) (Figure 1A) is a compound isolated from seeds ofBrucea javanica (Linn.) Merr (Simaroubaceae) (Yadanzi) that has been widely used in traditional Chinese medicine. Yadanzi oil emulsion has demonstrated anti-inflammatory activity via the suppression of NF- $x \mathrm{~B}$ activation (Huang et al., 2017). However, evidence for the anti-inflammatory activity of YDZG has not been shown. In this study, we aimed to illustrated anti-inflammatory activities and mechanism of YDZG in vitro and in vivo.

\section{Methods}

\section{Reagent}

YDZG (>98\%) was isolated in our laboratory and its purity was determined by HPLC. LPS (Escherichia coli , serotype 0111: B4) was purchased from Sigma-Aldrich (St. Louis, MO, USA). DMEM and FBS were purchased from Life Technologies/Gibco Laboratories (Grand Island, NY, USA). ELISA kits for IL- 
$1 \beta$, IL-6 and TNF- $\alpha$ were purchased from Neobioscience (Shenzhen, China). Antibodies against p65, pp65, p-IKK- $\alpha / \beta$, IKK- $\alpha$, IKK- $\beta$, p-I $\chi$ B- $\alpha$, I $\chi$ B- $\alpha$, NLRP3, IL-1 $\beta$, cleaved-IL-1 $\beta$, caspase-1, cleaved-caspase-1, and GAPDH were purchased from Cell Signaling Technologies (Beverly, MA, USA). Antibodies against TRIM31 were purchased from Thermo Fisher Scientific (Grand Island, NY, USA). Oligonucleotide primers for Nlrp3, IL-1 $\beta$ and GAPDH were synthesized by Invitrogen (Nanning, China). 4-Amino-5-methylamino20,70-difluorofluorescein diacetate (DAF-FM), a protein A/G magnetic bead kit, RT-PCR, and quantitative PCR (qPCR) kits, were purchased from Life Technologies/Thermo Fisher Scientific (Grand Island, NY, USA). Plasmids of pcDNA3-N-Flag-NLRP3 and pEGFP-C2-NLRP3 were purchased from Addgene (Beijing, China).

\section{Cell culture}

RAW264.7 macrophages were obtained from the cell bank of the Chinese Academy of Sciences (Shanghai, China). J774A.1 macrophages were purchased from BeNa Culture Collection (Jiangsu, China). Human THP-1 and HEK293T cells were purchased from American Type Culture Collection (Manassas, VA, USA). Cells were cultured in DMEM or RPMI 1640 supplemented with $10 \%$ FBS. Cells were maintained at $37^{\circ} \mathrm{C}$ under a humidified atmosphere of $5 \% \mathrm{CO} 2$ in an incubator.

\section{Transient transfection}

HEK293T cells were seeded into a dish $\left(10 \mathrm{~cm}\right.$, i.d.) at $10^{6}$ cells, and were incubated overnight. Plasmids of pcDNA3-N-Flag-NLRP3 or pEGFP-C2-NLRP3 obtained from Addgene were transfected using TurboFect transfection reagents (Thermo Fisher Scientific) for $24 \mathrm{~h}$. The transfected cells were seeded into a dish $(5$ $\mathrm{cm}$, i.d.) at a density of $5 \times 10^{5}$ cells, and were incubated overnight. The cells were pretreated with YDZG $(20 \mu \mathrm{M})$ for $1 \mathrm{~h}$ and stimulated with LPS $\left(1 \mu \mathrm{g} \cdot \mathrm{mL}^{-1}\right)$ for $6 \mathrm{~h}$, then treated with ATP for 30 min before harvesting.

MTT assayRAW264.7, J774A.1, and THP-1 cells were seeded into 96-well plates at a density of $4 \times 10^{4}$, $1 \times 10^{4}, 2 \times 10^{4}$ cells per well and were incubated overnight. Then, the cells were treated with different concentration of YDZG for $24 \mathrm{~h}$, and an MTT assay was used to determine cytotoxicity according to our previous report(Gao et al., 2015).

Determination of NORAW264.7 cells were plated in 24 -well plates at a density of $5 \times 10^{5}$ per well overnight. The cells were pretreated with YDZG $(20,40$ or $80 \mu \mathrm{M})$ for $1 \mathrm{~h}$, then LPS $\left(1 \mu \mathrm{g} \cdot \mathrm{mL}^{-1}\right)$ was added to the YDZG containing medium, followed by $18 \mathrm{~h}$ culture. Treated cells were collected and stained with DAF-FM $(1 \mu \mathrm{M})$ for an additional $1 \mathrm{~h}$. The fluorescence signal was determined by FACScan flow cytometry using the FITC or PE channel.

\section{Enzyme-linked immunosorbent assay}

The concentrations of mouse IL- $1 \beta$, mouse TNF-a, mouse IL-6, human IL-1 $\beta$, human TNF-a, and human IL-6 were measured using ELISA kits according to the manufacturer's instruction.

ImmunofluorescenceImmunofluorescence analysis of $\mathrm{NF}-x \mathrm{~B} / \mathrm{p} 65$ was conducted as previously described(Gao et al., 2016). Briefly, $2 \times 10^{5}$ RAW264.7 or THP-1 cells were seeded into a 35-mm glass-bottom SPL confocal dish overnight. The cells were pretreated with YDZG for $1 \mathrm{~h}$, then stimulated with LPS (1 $\left.\mu \mathrm{g} \cdot \mathrm{mL}^{-1}\right)$ for another $2 \mathrm{~h}$. Then, the primary antibody anti-NF- $\chi \mathrm{B} / \mathrm{p} 65$ (1:100) and secondary antibody goat anti-rabbit Alexa Fluor 568 (1:200) were applied. Cells were fixed and stained with Hoechst $33342(1 \mu \mathrm{M})$ for imaging. The immunofluorescence analysis of Caspase-1 p20 was conducted in a similar manner to NF$x$ /p65, but the primary antibody anti-Caspase-1p20 (1:200) and secondary antibody goat anti-rabbit Alexa Fluor 488 (1:200) were applied. HEK293T cells transiently transfected with plasmids encoding GFP-NLRP3 were cultured for $48 \mathrm{~h}$. Nuclei were stained with Hoechst $33342(1 \mu \mathrm{M})$. Cells were examined using a confocal laser microscope (Leica, Wetzlar, Germany).

Immunoblotting and immunoprecipitationProtein samples were collected from treated cells, and protein concentrations were examined using a BCA protein kit (Waltham, MA, USA). Cytoplasmic and nuclear 
proteins were extracted according to the kit manufacturer's instructions (Beyond time, Shanghai, China). For immunoprecipitation, the antigen samples were combined with specific antibody, then incubated overnight at $4{ }^{\circ} \mathrm{C}$ with mixing. Protein $\mathrm{A} / \mathrm{G}$ Magnetic Beads were washed and collected with a magnetic stand, then incubated with antigen sample/antibody mixture. After $1 \mathrm{~h}$ of incubation, beads were washed three times with IP buffer. Immunoprecipitates were eluted using SDS-PAGE reducing sample buffer. For immunoblot analysis, an equivalent amount of each protein sample was subjected to SDS-PAGE gel electrophoresis and transferred to PVDF membranes. Membranes were then blocked with $5 \%$ non-fat milk dissolved in Trisbuffered saline Tween 20 buffer for $1 \mathrm{~h}$, then probed with primary antibodies (1:1000) overnight at $4{ }^{\circ} \mathrm{C}$. Corresponding secondary antibodies (1:5000) were then added for a further $1 \mathrm{~h}$ at $25^{\circ} \mathrm{C}$. Protein band signals were detected using SuperSignal West Femto maximum sensitivity substrate (Pierce Biotechnology) under visualization in a ChemiDoc MP Imaging System (Bio-Rad, Hercules, CA, USA).

\section{Quantitative real-time PCR (qRT-PCR)}

Total RNA was extracted from each sample using a TRIzol assay kit (St. Louis, MO, USA). Then, $1 \mu$ g of RNA sample was applied to qRT-PCR using a qPCR master mix kit. SYBR green was incorporated into PCR amplification. The oligonucleotide primers derived from human for IL-1 $\beta$ were AAACAGATGAAGTGCTCCTTCCAGG (forward) and GGGAACTGGGCAGACTCAAA (reverse), and for GAPDH these were TGCCTCCTGCACCACCAACT (forward) and CCCCGTTCAGCTCAGGGATGA (reverse).

\section{Animal experiments and ethical statement}

All animal care and experimental procedures were approved by the Guangxi University of Chinese Medicine Animal Policy and Welfare Committee (Approval Document No. SYXK-GUI-2019-0001). All animals received humane care according to the Local Guide for the Care and Use of Laboratory Animals of Guangxi University of Chinese Medicine. Animal studies are reported in compliance with the ARRIVE guidelines (Kilkenny et al., 2010; Mcgrath \& Lilley, 2015).

Male BABL/C mice weighing 18-22 g, were obtained from Hunan SJA Laboratory Animal Co. Ltd (Hunan, China). The mice were maintained on a $12 \mathrm{~h}$ light/dark cycle under specific pathogen-free conditions. Mice were acclimatized to the laboratory for 3 days, then randomly assigned to one of five groups ( $\mathrm{n}=8$ per group). The groups consisted of vehicle control (CON), an LPS-induced ALI group (4 mg. $\mathrm{kg}^{-1} \mathrm{or} 15 \mathrm{mg} \cdot \mathrm{kg}^{-1}$; intratracheally, i.t.), a dexamethasone treatment group $\left(5 \mathrm{mg} \cdot \mathrm{kg}^{-1}\right.$; dexamethasone intraperitoneally, i.p.), a YDZG treatment of LPS-induced ALI ( $5 \mathrm{mg} \cdot \mathrm{kg}^{-1}$; YDZG; intravenously, i.v.), and a second YDZG treatment of LPS-induced ALI (10 mg. $\mathrm{kg}^{-1}$; YDZG; intravenously, i.v.). LPS induction of ALI was performed according to a method previously described, with slight modifications (Spoelstra et al., 2007). Briefly, mice were anesthetized using pentobarbital sodium ( $48 \mathrm{mg} \cdot \mathrm{kg}^{-1} ;$ i.p.), then mice treated with non-invasive intratracheal instillation of LPS into lung tissue $\left(4 \mathrm{mg} \cdot \mathrm{kg}^{-1}\right.$ or $15 \mathrm{mg} \cdot \mathrm{kg}^{-1}$; i.t.). Control mice received sterile saline. In the Dexamethasone group, mice were given dexamethasone $\left(5 \mathrm{mg} \cdot \mathrm{kg}^{-1}\right.$; i.p. $) 6 \mathrm{~h}$ after ALI induction. ALI + YDZG 5 group mice were given YDZG ( $5 \mathrm{mg} \cdot \mathrm{kg}^{-1}$; i.v.) $2 \mathrm{~h}$ before ALI induction; Same concentration of YDZG was also given at $6 \mathrm{~h}$ and $12 \mathrm{~h}$ after ALI induction. ALI + YDZG 10 group mice were given YDZG (10 mg. $\mathrm{kg}^{-1}$; i.v.) $2 \mathrm{~h}$ before ALI induction, and were given YDZG $6 \mathrm{~h}$ and $12 \mathrm{~h}$ after ALI induction. Mice were sacrificed by cervical dislocation under ether anesthesia. Serum, bronchoalveolar lavage fluid (BALF, see below), and lung tissue samples were collected and stored at $-80{ }^{\circ} \mathrm{C}$. Serum and BALF samples were used for cytokine measurements via TNF- $\alpha$, IL-6 and IL-1 $\beta$ ELISA kits. Lung homogenate was prepared from lung tissue and was used for cytokine detection by ELISA. Portions of lung sections were fixed in $4 \%$ paraformaldehyde and embedded in paraffin for histological analysis (see below). The remaining lung tissue was used for protein lysate preparation for immunoblotting.

\section{Histology}

Lung tissue was harvested $24 \mathrm{~h}$ after LPS treatment. Lung tissue was fixed with $4 \%$ paraformaldehyde for $48 \mathrm{~h}$, then dehydrated, embedded in paraffin, and sliced. The slices were stained with hematoxylin and eosin $(\mathrm{H} \& \mathrm{E})$ and were viewed under a light microscope. NLRP3 expression was examined by immunohistochemistry using a rabbit anti-mouse NLRP3 antibody. 


\section{Hematology analysis}

Blood was collected from mouse orbit. The blood sample was further processed with h EDTA. White blood cell and neutrophil counts from blood were determined using an auto hematology analyzer (Mindray, Shenzhen, China).

\section{Assessment of respiratory mechanics}

Twelve hours after LPS instillation into lung tissue, mice were anesthetized as described above, tracheostomized, and a rigid-type cannula (2-mm i.d.) was inserted into the trachea and firmly tied in place. The cannula was connected to a small animal ventilator (bestlab, Beijing, China) and resistance of lung $(\mathrm{RL})$, resistance of expiration (Re), and respiratory lung compliance (Cdyn) of mice were measured.

\section{BALF preparation}

BALF was harvested via injection and retraction of PBS-EDTA three times. Approximately $0.8 \mathrm{~mL}$ BALF was acquired and centrifuged at $1000 \times \mathrm{g}$ for $5 \mathrm{~min}$ at $4{ }^{\circ} \mathrm{C}$. The supernatant was immediately stored at -80 ${ }^{\circ} \mathrm{C}$.

Data analysisAll data and statistical analyses comply with the recommendations for experimental design and analysis in pharmacology. All results are presented as the means \pm SEM. For statistical analysis, the significance of the intergroup differences was analyzed by one-way ANOVA with Dunnett's multiple comparisons test using GraphPad Prism 6.0 software. A significant difference was defined as $P<0.05$.

\section{Results}

\section{YDZG inhibits NLRP3 inflammasome activation.}

The NLRP3 inflammasome is important for macrophage activation and the formation of the inflammasome complex during inflammatory process (Elliott \& Sutterwala, 2015). In addition, IL-1 $\beta$ is an important pro-inflammatory cytokine and must be cleaved from its inactive form (pro-IL-1 $\beta$ ) to the mature form by caspase 1 (He et al., 2016). To test whether YDZG can block NLRP3 activation, the impact of YDZG on NLRP3 inflammasome complex formation, caspase-1 activation, and IL-1 $\beta$ secretion was examined. YDZG $(40 \mu \mathrm{M})$ significantly blocked the formation of the NLRP3 inflammasome induced by LPS and ATP (Figure 1B) and showed no significant cytotoxicity (Figure S1). Immunofluorescence staining results revealed that YDZG decreased caspase-1 p20 activation (Figure 1C), resulting in the decrease of mature IL- $1 \beta$ and cleaved caspase-1 release into supernatants (Figures 1D-E). Corresponding with IL-1 $\beta$ release, YDZG suppressed LPS- plus ATP-induced IL-1 $\beta$ gene expression (Figure 1F). In summary, these results suggested that YDZG blocked NLRP3 inflammasome. The mechanism of how YDZG blocks NLRP3 inflammasome activation was then studied.

\section{YDZG inhibits NLRP3 inflammasome assembly by inhibiting NLRP3 expression.}

The ability of YDZG to inhibit NLRP3 inflammasome activation by promoting protein degradation of inflammasome components was investigated. In resting J774A.1 cells, YDZG treatment was associated with reduced NLRP3 protein expression, however there was no influence on ASC and caspase-1 protein expression (Figure 2A). When J774A.1 cells were stimulated with LPS for different time, YDZG greatly decreased NLRP3 protein expression, with no effects on ASC and caspase-1 protein expression (Figure 2B). These results suggested that YDZG could greatly decrease NLRP3 expression before the functional NLRP3 inflam-

masome is activated. An essential step for NLRP3 inflammasome assembly is via simultaneous exposure to a second NLRP3-specific trigger, such as extracellular ATP, alum, or the pore-forming toxin nigericin. We evaluated the effects of YDZG on the components of NLRP3 inflammasome after the formation of NLRP3 inflammasome complexes. When J774A.1 cells were stimulated with YDZG before LPS and ATP treatment, YDZG led to a sharp decrease in NLRP3 expression (Figure 2C). YDZG consistently led to a large decrease in NLRP3 protein expression in a dose-dependent manner in THP-1 cells (Figures 2D- E). Importantly, using NLRP3-flag plasmid, we found that YDZG treatment led to much less NLRP3 protein expression in 
HEK293T cells (Figure 2F). Furthermore, immunofluorescence staining analysis revealed that YDZG reversed LPS-induced high expression of NLRP3 in HEK293T cells (Figure 2G). Taken together, our data showed that YDZG inhibited NLRP3 expression to block NLRP3 inflammasome assembly.

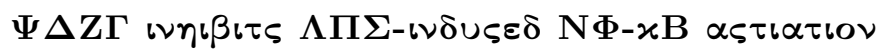

YDZG was found to suppress NF- $\varkappa$ B activation in J774A.1 (Figure 3A), THP-1 (Figure 3B), and RAW264.7 cells (Figure S2C), which is an essential step for NLRP3 activation. LPS increased the release of proinflammatory mediators such as NO (Figures S2A-B), TNF- $\alpha$ (Figure S2G) and IL-6 (Figures S2F-H), which were reversed by YDZG. Furthermore, immunofluorescence staining analysis revealed that YDZG inhibited the LPS-induced translocation of NF- $x \mathrm{~B} / \mathrm{p} 65$ into the nucleus of macrophage cells (Figure 3C, Figure S2E), which was consistent with the results of the changes in cytoplasmic and nuclear NF- $\chi \mathrm{B}$ expression (Figure 3D; Figure S2D). Overall, results suggested that YDZG blocked the NF- $\varkappa$ B pathway to suppress NLRP3 expression.

\section{YDZG suppresses mitochondrial reactive oxygen species (ROS) generation.}

Reactive oxygen species (ROS) plays an important role in NLRP3 inflammasome assembly. Nuclear factor E2-related factor 2 (Nrf2) is a basic leucine zipper redox-sensitive transcription factor known for its antioxidant and anti-inflammatory properties (Zhang et al., 2013). Previous studies indicated that mitochondrial ROS activates NLRP3 inflammasome activation through the Nrf2 pathway(Hu et al., 2018; Zhao et al., 2014). In the present study, we investigated whether YDZG inhibited ROS generation to block NLRP3. As shown in Figure 4A, B, and E, YDZG sharply inhibited LPS-induced ROS generation. Using the Mito Sox, a mitochondrial ROS fluorescence detector, we found that YDZG inhibited mitochondrial ROS generation (Figure 4C). In addition, our results indicated that YDZG promoted Nrf2 translocation from the cytoplasm into the nucleus (Figure 4D-F), suggesting that YDZG inhibited mitochondrial ROS generation via the Nrf2 pathway.

\section{YDZG enhances TRIM31 expression to promote NLRP3 protein degradation.}

Previous studies showed that CY-09 (Jiang et al., 2017) and OLT1177 (Marchetti et al., 2018) directly bind to NLRP3 to attenuate NLRP3 inflammasome activation. We investigated the ability of YDZG to directly bind to NLRP3 by thermal shift assay. Results suggested that YDZG does not directly bind to NLRP3 (Figure S3). A recent study found that the TRIM31 attenuates NLRP3 inflammasome activation by promoting proteasomal degradation of NLRP3 (Song et al., 2016). TRIM31 directly bound to NLRP3, then promoted K48-linked polyubiquitination and proteasomal degradation of NLRP3 in both resting and activated macrophages (Song et al., 2016). We found that YDZG enhanced TRIM31 expression in resting J774A.1 (Figure 5A) and THP-1 (Figure 5B) cells. Since constitutively expressed TRIM31 can bind to NLRP3, promoting K48-linked ubiquitination and proteasomal degradation of NLRP3, we investigated whether YDZG could mediate the expression of TRIM31 to promote NLRP3 degradation. After the NLRP3 inflammasome was activated by LPS and ATP, YDZG treatment enhanced TRIM31 protein expression (Figures 5C- D), resulting in the inhibition of NLRP3 expression and subsequent inflammasome activation. Furthermore, as shown in Figure 5E, YDZG increased the formation of TRIM31-NLRP3 complexes. In summary, these findings indicated that YDZG enhanced TRIM31 expression to promote proteasomal degradation of NLRP3 in both resting and activated macrophages.

\section{YDZG ameliorates LPS-induced acute lung injury in mice.}

A lethal dose of LPS was intratracheally injected into lung tissue of mice with non-invasive assay, and their survival rate were recorded. In the LPS treated group, all mice died within $96 \mathrm{~h}$ after LPS injection, however, mice pretreated with YDZG $\left(5 \mathrm{mg} \cdot \mathrm{kg}^{-1}\right)$ had a significantly greater survival rate (Figure $\left.6 \mathrm{~A}\right)$. In addition, results of respiratory mechanic analysis indicated that LPS increased lung functional indexes like the resistance of lung (RL) and resistance of expiration (Re), and decreased respiratory lung compliance (Cdyn), of which the effects of RL (Figure 6B), Re (Figure 6C), and Cdyn (Figure 6D) were significantly were reversed by YDZG pretreatment. Furthermore histological analysis indicated that LPS triggered the 
infiltration of antibacterial cells, thickened the alveolar wall, and destroyed the normal lung tissue structure; YDZG treated groups prevented LPS-induced acute lung injury (Figure 6E).

\section{YDZG reduces LPS-induced infiltration of inflammatory cells and cytokine levels.}

LPS-treated mice had more leukocyte (Figure 7A) and neutrophil (Figure 7B) counts in blood than that of the control. However, LPS- and YDZG-treated mice had significantly fewer leukocytes and neutrophils than mice treated with LPS alone. Moreover, LPS-challenged animals showed significantly greater MPO activity in lung tissue (a marker for neutrophils) than the control. Meanwhile, YDZG pretreated-mice had less MPO activity than those treated with LPS alone (Figure 7C). In the LPS-induced ALI model, YDZG decreased the LPS-induced inflammatory cytokines TNF- $\alpha$ (Figure 7D) and IL-6 (Figure 7E) in BALF. Similar results were found in serum (Figures 7F- G) and lung tissue samples (Figures 6H- I), respectively. Thus, YDZG reduced the infiltration of inflammatory cells and cytokine levels to prevent ALI.

\section{YDZG inhibits NLRP3 inflammasome activation in lung tissue.}

Since YDZG exhibited NLRP3 inhibitory activity in vitro, the effects of YDZG on LPS-induced mechanism in the lungs of the ALI animal model were examined. IL- $1 \beta$ release was measured in BALF, serum, and lung homogenate by ELISA. Significantly, YDZG suppressed IL- $1 \beta$ expression in BALF (Figure 8A), serum (Figure 8B), and lung homogenate (Figure 8C), respectively. To determine whether YDZG could inhibit activation of the NLRP3 inflammasome in ALI mice, the level of NLRP3 and caspase-1 p20 was measured in lung homogenate by western blot analysis. Results indicated that LPS increased NLRP3 and caspase-1 p20 expression in the lung homogenate of ALI mice, which was reversed by YDZG (Figure 8D), suggesting that administration of YDZG could effectively attenuate activation of the NLRP3 inflammasome. In addition, using immunohistochemistry assay (Figure 8E), we examined the effects of YDZG on LPS-induced NLRP3 expression in situ of lung tissues. Corresponding to results of ELISA and western blotting assay, LPS induced the increase of NLRP3 expression in lung tissue, while YDZG inhibited NLRP3 expression. Taken together, our data demonstrated that YDZG prevented LPS-induced ALI through suppression of NLRP3 inflammasome activation.

\section{Discussion}

Brucea javanica (Linn.) Merr. (Simaroubaceae) is a traditional Chinese medicine commonly used for the treatment of inflammatory diseases and malaria (Huang et al., 2017; Yang et al., 2013). YDZG, a quassinoid glucoside, is firstly purified and identified by Zhang et al in 1983 (Zhang et al., 1983). However, as it stands now, quite few papers were found to report its bioactivity. Our previous study indicated that YDZG exhibited anti-complementary activity(Zhan et al., 2018). In the present study, evidence for the direct and covalent inhibition of NLRP3 expression by YDZG is provided. Also, the remarkable anti-inflammatory activity of YDZG was demonstrated through the attenuation of NLRP3 inflammasome activation both in vitro andin vivo. Taken together, these results suggest that YDZG can be used as a lead compound to design new therapeutics against NLRP3-driven diseases.

Previous studies have identified compounds that can directly target NLRP3 to suppress NLRP3 activation (Jiang et al., 2017; Marchetti et al., 2018). In contrast, our results showed that YDZG did not directly bind to NLRP3. However, YDZG could enhance TRIM31 expression, an NLRP3 protein inhibitor, to block NLRP3 inflammasome activation. In addition, activation of the NLRP3 inflammasome is thought be regulated at transcriptional and post-translational levels (Jo et al., 2015). The first signal in inflammasome activation is a priming signal, induced by the toll-like receptor (TLR)/nuclear factor (NF)-kB pathway, to upregulate NLRP3 expression (Swanson et al., 2019). NF- $x$ B plays an important role in regulating immune responses (Liang et al., 2004; Zhang \& Ghosh, 2001). However, aberrant activation of NF- $\chi \mathrm{B}$ is linked to an upregulation of pro-inflammatory mediators in ALI (Everhart et al., 2006). NF- $\chi \mathrm{B}$ binding sequences have also been identified in pro-inflammatory genes such as inducible IL-6 and TNF- $\alpha$ (Cho et al., 2007; Xie et al., 2012). In our study, results suggested that YDZG inhibited LPS-induced NF- $\chi \mathrm{B}$ activation to block the expression of NLRP3. 
ROS production can stimulate NLRP3 inflammasome activation and inflammatory cascade reactions (Heid et al., 2013; Shirasuna et al.; Zhou et al.). When stimulated by oxidative stress, Nrf2 is dissociated from Keap1, transferred to the nucleus, and combined with antioxidant response elements (ARE), where it activates the transcription of the HO-1 gene to achieve antioxidant effects (Bao et al.; Sawle et al.; Yang et al., 2015). A recent study found that Nrf2 negatively regulates NLRP3 inflammasome activity by inhibiting ROS (Hu et al.). Our results indicated that YDZG promoted Nrf2 translocation from the cytoplasm into the nucleus and inhibited ROS generation.

As a primary organ of respiration, the lung encounters constant exposure to foreign particles and infectious agents. Chronic respiratory diseases and acute lung injuries are common and widespread problems affecting millions of people worldwide, especially in developing countries (Bellani et al., 2016; Guerin et al., 2015; Lorente et al., 2015). In spite of considerable efforts, there are still no Food and Drug Administrationapproved treatments for ALI (Standiford \& Ward, 2016). In this study, the protective effect of YDZG on an LPS-induced ALI model was evaluated. Results revealed that YDZG could significantly protect mice from lung damage and respiratory dysfunction. Recent data has shown that NLRP3 inflammasome is involved in the development of ALI (Dolinay et al., 2012). IL-1 $\beta$ is a central pro-inflammatory cytokine in the initiation of inflammation and transient expression of IL-1 $\beta$ alone can induce acute lung injury (Kolb et al., 2001). Additionally, application of the neutralizing antibodies for IL-18, IL-1 $\beta$, and IL-1R antagonists has reduced lung injury on ALI mouse and rat models (Kuipers et al., 2012; Mulligan \& Ward, 1992; Wu et al., 2013). In this study, YDZG decreased IL-1 $\beta$ in the BALF, serum, and lung tissue of mice and reduced NLRP3 and caspase-1 p20 in the lung.

In summary, our results indicated that YDZG effectively inhibited NLRP3 inflammasome activation in macrophages and mouse model of ALI. We discovered that YDZG suppressed NLRP3 inflammasome via the reduction of NF- $x \mathrm{~B}$ and Nrf2 activation and the promotion of TRIM31 expression, suggesting that YDZG could be a potential agent of treatment with NLRP3-driven ALI.

\section{REFERENCES}

Bao Y, Meng X, Liu F, Wang F, Yang J, Wang H, et al. Protective effects of osthole against inflammation induced by lipopolysaccharide in BV2 cells. Molecular Medicine Reports,17:4561-4566.

Bellani G, Laffey JG, Pham T, Fan E, Brochard L, Esteban A, et al. (2016). Epidemiology, patterns of care, and mortality for patients with acute respiratory distress syndrome in intensive care units in 50 countries. Jama 315: 788-800.

Cho J-W, Lee K-S, \& Kim C-W (2007). Curcumin attenuates the expression of IL-1 $\beta$, IL-6, and TNF- $\alpha$ as well as cyclin

$\mathrm{E}$ in TNF- $\alpha$-treated HaCaT cells; NF- $\chi \mathrm{B}$ and MAPKs as potential upstream targets. International journal of molecular medicine 19:469-474.

Dolinay T, Kim YS, Howrylak J, Hunninghake GM, An CH, Fredenburgh L, et al. (2012). Inflammasomeregulated cytokines are critical mediators of acute lung injury. American journal of respiratory and critical care medicine 185: 1225-1234.

Elliott EI, \& Sutterwala FS (2015). Initiation and perpetuation of NLRP 3 inflammasome activation and assembly. Immunological reviews 265: 35-52.

Everhart MB, Han W, Sherrill TP, Arutiunov M, Polosukhin VV, Burke JR, et al. (2006). Duration and intensity of NF- $x \mathrm{~B}$ activity determine the severity of endotoxin-induced acute lung injury. The Journal of Immunology 176: 4995-5005.

Gao H, Cui Y, Kang N, Liu X, Liu Y, Zou Y, et al. (2017). Isoacteoside, a dihydroxyphenylethyl glycoside, exhibits anti-inflammatory effects through blocking toll-like receptor 4 dimerization. British journal of pharmacology 174: 2880-2896. 
Gao H, Sun W, Zhao J, Wu X, Lu J-J, Chen X, et al. (2016). Tanshinones and diethyl blechnics with anti-inflammatory and anti-cancer activities from Salvia miltiorrhiza Bunge (Danshen). Scientific Reports 6: 33720 .

Gao H, Sun W, Zhao W, Hao W, Leung C-H, Lu J, et al. (2015). Total tanshinones-induced apoptosis and autophagy via reactive oxygen species in lung cancer 95D cells. The American journal of Chinese medicine 43: $1265-1279$.

Guerin C, Bayle F, Leray V, Debord S, Stoian A, Yonis H, et al.(2015). Open lung biopsy in nonresolving ARDS frequently identifies diffuse alveolar damage regardless of the severity stage and may have implications for patient management. Intensive care medicine 41: 222-230.

He Y, Hara H, \& Núñez G (2016). Mechanism and regulation of NLRP3 inflammasome activation. Trends in biochemical sciences 41:1012-1021.

Heid ME, Keyel PA, Kamga C, Shiva S, Watkins SC, \& Salter RD (2013). Mitochondrial reactive oxygen species induces NLRP3-dependent lysosomal damage and inflammasome activation. The Journal of Immunology 191: $5230-5238$

Hu Q, Zhang T, Yi L, Zhou X, \& Mi M(2018). Dihydromyricetin inhibits NLRP3 inflammasome-dependent pyroptosis by activating the Nrf2 signaling pathway in vascular endothelial cells. Biofactors,44:123-136.

Hu Q, Zhang T, Yi L, Zhou X, \& Mi M (2018). Dihydromyricetin inhibits NLRP3 inflammasome-dependent pyroptosis by activating the Nrf2 signaling pathway in vascular endothelial cells. Biofactors 44: 123-136.

Huang Y-F, Zhou J-T, Qu C, Dou Y-X, Huang Q-H, Lin Z-X, et al.(2017). Anti-inflammatory effects of Brucea javanica oil emulsion by suppressing NF- $\varkappa \mathrm{B}$ activation on dextran sulfate sodium-induced ulcerative colitis in mice. Journal of ethnopharmacology 198:389-398.

Jiang H, He H, Chen Y, Huang W, Cheng J, Ye J, et al. (2017). Identification of a selective and direct NLRP3 inhibitor to treat inflammatory disorders. Journal of Experimental Medicine 214:3219-3238.

Jo E-K, Kim JK, Shin D-M, \& Sasakawa C (2015). Molecular mechanisms regulating NLRP3 inflammasome activation. Cellular \& molecular immunology 13: 148-159.

Johnson ER, \& Matthay MA (2010). Acute lung injury: epidemiology, pathogenesis, and treatment. Journal of aerosol medicine and pulmonary drug delivery 23: 243-252.

Kilkenny C, Browne W, Cuthill IC, Emerson M, \& Altman DG (2010). Animal research: reporting in vivo experiments: the ARRIVE guidelines. British journal of pharmacology 160: 1577-1579.

Kolb M, Margetts PJ, Anthony DC, Pitossi F, \& Gauldie J (2001). Transient expression of IL-1 $\beta$ induces acute lung injury and chronic repair leading to pulmonary fibrosis. The Journal of clinical investigation 107: 1529-1536.

Kuipers MT, Aslami H, Janczy JR, van der Sluijs KF, Vlaar AP, Wolthuis EK, et al. (2012). Ventilatorinduced lung injury is mediated by the NLRP3 inflammasome. Anesthesiology: The Journal of the American Society of Anesthesiologists 116: 1104-1115.

Liang Y, Zhou Y, \& Shen P (2004). NF-kappaB and its regulation on the immune system. Cell Mol Immunol, 2004, 1: 343-350.

Liu B, Zhang M, Chu H, Zhang H, Wu H, Song G, et al. (2017). The ubiquitin E3 ligase TRIM31 promotes aggregation and activation of the signaling adaptor MAVS through Lys63-linked polyubiquitination. Nature immunology 18: 214.

Lorente JA, Cardinal-Fernández P, Muñoz D, Frutos-Vivar F, Thille AW, Jaramillo C, et al. (2015). Acute respiratory distress syndrome in patients with and without diffuse alveolar damage: an autopsy study. Intensive care medicine 41: 1921-1930. 
Marchetti C, Swartzwelter B, Gamboni F, Neff CP, Richter K, Azam T, et al. (2018). OLT1177, a $\beta$-sulfonyl nitrile compound, safe in humans, inhibits the NLRP3 inflammasome and reverses the metabolic cost of inflammation. Proceedings of the National Academy of Sciences 115: E1530-E1539.

Mcgrath JC, \& Lilley E (2015). Implementing guidelines on reporting research using animals (ARRIVE etc.): new requirements for publication in BJP. British journal of pharmacology, 172: 3189-3193.

Mohan A, Sharma SK, \& Bollineni S (2008). Acute lung injury and acute respiratory distress syndrome in malaria. Journal of Vector Borne Diseases 45: 179-193.

Mulligan M, \& Ward P (1992). Immune complex-induced lung and dermal vascular injury. Differing requirements for tumor necrosis factor-alpha and IL-1. The Journal of Immunology 149: 331-339.

Rubenfeld GD, Caldwell E, Peabody E, Weaver J, Martin DP, Neff M, et al. (2005). Incidence and outcomes of acute lung injury. New England Journal of Medicine 353: 1685-1693.

Sawle P, Foresti R, Mann BE, Johnson TR, Green CJ, \& Motterlini R Carbon monoxide-releasing molecules (CO-RMs) attenuate the inflammatory response elicited by lipopolysaccharide in RAW264.7 murine macrophages. 145: 800-810.

Schell-Chaple HM, Puntillo KA, Matthay MA, \& Liu KD (2015). Body temperature and mortality in patients with acute respiratory distress syndrome. American Journal of Critical Care 24: 15-23.

Shirasuna, Koumei, Suzuki, Hirotada, Iwata, Hisataka, et al (2016). Palmitic acid induces interleukin-1 beta secretion via NLRP3 inflammasomes and inflammatory responses through ROS production in human placental cells, Journal of reproductive immunology, 116: 104-112.

Song H, Liu B, Huai W, Yu Z, Wang W, Zhao J, et al. (2016). The E3 ubiquitin ligase TRIM31 attenuates NLRP3 inflammasome activation by promoting proteasomal degradation of NLRP3. Nature communications 7: $1-11$.

Spoelstra E, Ince C, Koeman A, Emons V, Brouwer L, Van Luyn M, et al. (2007). A novel and simple method for endotracheal intubation of mice. Laboratory animals 41: 128-135.

Standiford TJ, \& Ward PA (2016). Therapeutic targeting of acute lung injury and acute respiratory distress syndrome. Translational Research 167: 183-191.

Sutterwala FS, Haasken S, \& Cassel SL (2014). Mechanism of NLRP3 inflammasome activation. Annals of the New York Academy of Sciences 1319: 82-95.

Swanson KV, Deng M, \& Ting JP-Y (2019). The NLRP3 inflammasome: molecular activation and regulation to therapeutics. Nature Reviews Immunology 19: 477-489.

Tschopp J, \& Schroder K (2010). NLRP3 inflammasome activation: The convergence of multiple signalling pathways on ROS production? Nature reviews immunology 10: 210-215.

Ware LB, \& Matthay MA (2000). The acute respiratory distress syndrome. New England Journal of Medicine 342: 1334-1349.

Wu J, Yan Z, Schwartz DE, Yu J, Malik AB, \& Hu G (2013). Activation of NLRP3 inflammasome in alveolar macrophages contributes to mechanical stretch-induced lung inflammation and injury. The Journal of Immunology 190: 3590-3599.

Xie C, Kang J, Li Z, Schauss AG, Badger TM, Nagarajan S, et al.(2012). The açaí flavonoid velutin is a potent anti-inflammatory agent: blockade of LPS-mediated TNF- $\alpha$ and IL-6 production through inhibiting NF- $x$ B activation and MAPK pathway. The Journal of nutritional biochemistry 23: 1184-1191.

Yang HL, Lin SW, Lee CC, Lin KY, Liao CH, Yang TY, et al. (2015). Induction of Nrf2-mediated genes by Antrodia salmonea inhibits ROS generation and inflammatory effects in lipopolysaccharide-stimulated RAW264.7 macrophages. Food \& Function,6:229-240. 
Yang J, Li S, Xie C, Ye H, Tang H, Chen L, et al. (2013). Anti-inflammatory activity of ethyl acetate fraction of the seeds of Brucea Javanica. Journal of ethnopharmacology 147: 442-446.

Yang Y, Wang H, Kouadir M, Song H, \& Shi F (2019). Recent advances in the mechanisms of NLRP3 inflammasome activation and its inhibitors. Cell Death Dis 10: 1-11.

Zhan Y, Tan T, Qian K, Yang S, Feng Y, \& Wen Q (2018). Quassinoids from seeds of Brucea Javanica and their anticomplement activities. Natural product research: 1-6.

Zhang G, \& Ghosh S (2001). Toll-like receptor-mediated NF- $x$ B activation: a phylogenetically conserved paradigm in innate immunity. The Journal of clinical investigation 107: 13-19.

Zhang H-F, Shi L-J, Song G-Y, Cai Z-G, Wang C, \& An R-J (2013). Protective effects of matrine against progression of high-fructose diet-induced steatohepatitis by enhancing antioxidant and anti-inflammatory defences involving Nrf2 translocation. Food and chemical toxicology 55: 70-77.

Zhang J-S, Lin L-Z, Chen Z, Xu RS \& Sun XY (1983). Studies on the chemical constituents of brucea javanica ii. Acta Chimica Sinica, 2:149-152.

Zhao C, Gillette DD, Li X, Zhang Z, \& Wen H (2014). Nuclear factor E2-related factor-2 (Nrf2) is required for NLRP3 and AIM2 inflammasome activation. Journal of Biological Chemistry 289: 17020-17029.

Zhou R, Yazdi AS, Menu P, \& Tschopp J A role for mitochondria in NLRP3 inflammasome activation. Nature 475: 122-122.

A

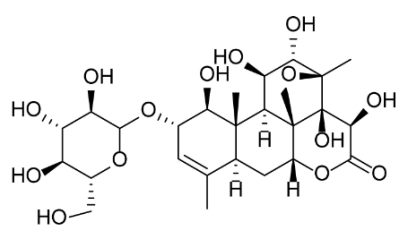

B

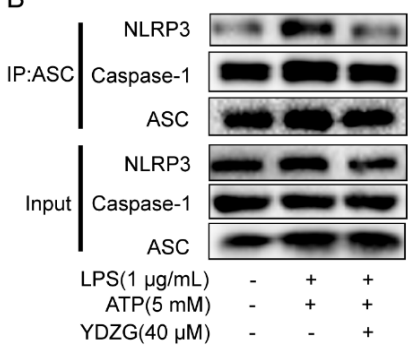

D

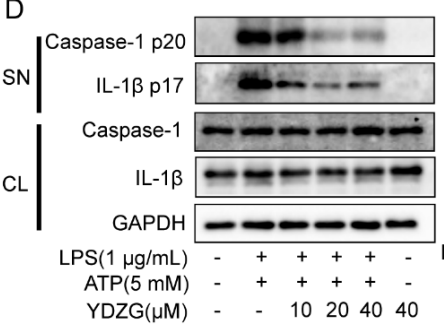

C

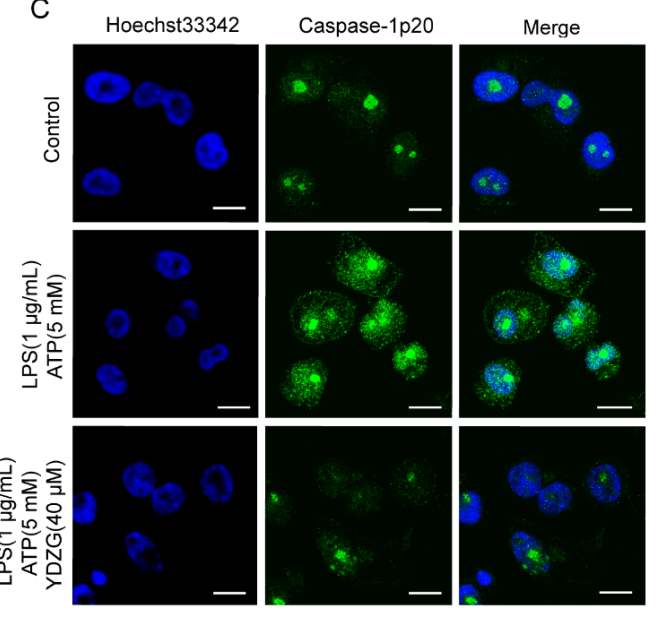

E

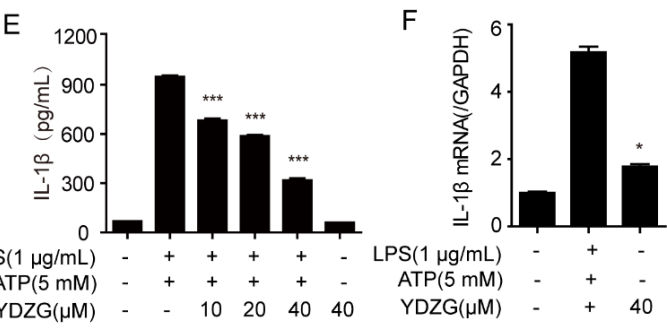

Figure 1 YDZG inhibits NLRP3 inflammasome activation. (A) Chemical structure of Yadanzigan (YDZG). (B) THP-1 cells were pretreated with $40 \mu \mathrm{M}$ YDZG for $1 \mathrm{~h}$ before being stimulated with LPS (1 $\left.\mu \mathrm{g} \cdot \mathrm{mL}^{-1}\right)$ for another $6 \mathrm{~h}$, and treated with ATP $(5 \mathrm{mM})$ for $30 \mathrm{~min}$ before harvesting. Proteins were isolated and immunoprecipitated with an antibody against ASC $(n=5)$. (C) THP-1 cells were pretreated with the 
indicated concentrations of YDZG for $1 \mathrm{~h}$ before being stimulated with LPS for another $2 \mathrm{~h}$, and were then treated with ATP $(5 \mathrm{mM})$ for $30 \mathrm{~min}$. Caspase-1 p20 was determined using the immunofluorescence assay described in the Methods section $(\mathrm{n}=3)$. The primary antibody anti-caspase- 1 p20 (1:200) and secondary antibody goat anti-Rabbit Alexa Fluor 488 (1:200) were employed (scale bar $=10 \mu \mathrm{m}$ ). (D) Immunoblot analysis of supernatants (SN) or cell lysates (CL) of THP-1 cells, primed with LPS, followed by stimulation with ATP for 30 min $(n=5)$. THP-1 cells were pretreated with the indicated concentrations of YDZG for 1 $\mathrm{h}$ before being stimulated with LPS for another $6 \mathrm{~h}$ and then treated with ATP $(5 \mathrm{mM})$ for $30 \mathrm{~min}$. The expression of IL-1 $\beta$, was determined using ELISA (E) and qRT-PCR (F) $(\mathrm{n}=6)$. Data are reported as mean $\pm \mathrm{SEM} ;{ }^{*} P<0.05$ compared with the LPS alone group.

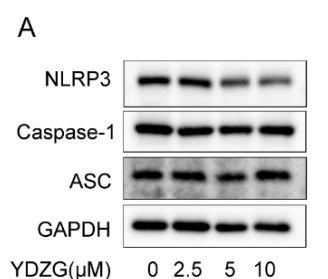

D

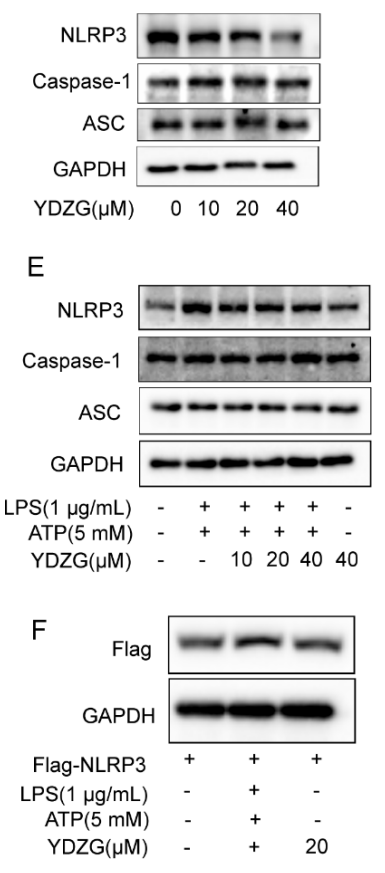

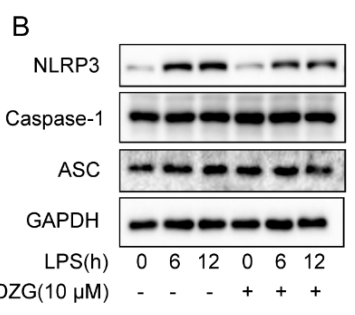
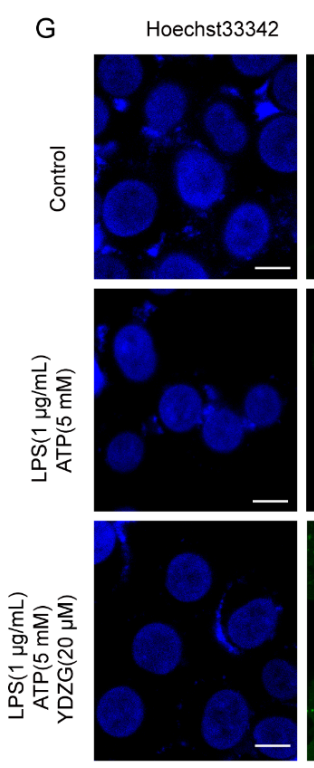
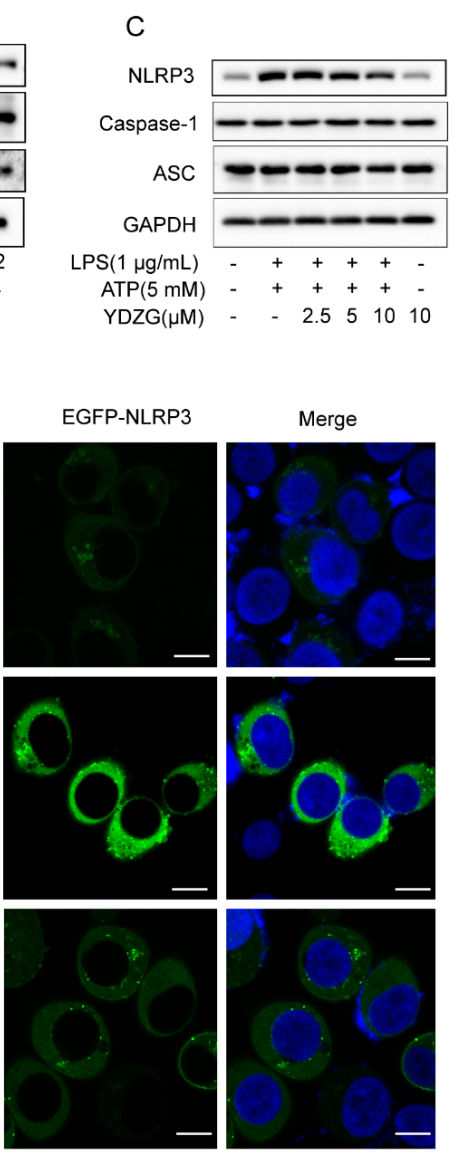

Figure 2 YDZG inhibits NLRP3 expression. J774A.1 (A) or THP-1 (D) cells were pretreated with the indicated concentrations of YDZG for $6 \mathrm{~h}$. NLRP3, caspase-1 and ASC expression was examined by Western blotting(n=5). (B) J774A.1 cells were treated or untreated with YDZG at $10 \mu \mathrm{M}$ for different times. NLRP3, caspase-1 and ASC expression was examined by Western blotting (n=5). J774A.1 (C) and THP-1 (E) cells were pretreated with $10 \mu \mathrm{M}$ YDZG $1 \mathrm{~h}$ before being stimulated with LPS $\left(1 \mu \mathrm{g} \cdot \mathrm{mL}^{-1}\right)$ for another $6 \mathrm{~h}$, and were then treated with ATP $(5 \mathrm{mM})$ for $30 \mathrm{~min}$ before harvesting. NLRP3, caspase-1 and ASC expression was examined by Western blotting $(\mathrm{n}=5)$. ( $\mathrm{F})$ Immunoblot analysis of extracts from HEK293T cells transfected with NLRP3 plasmid ( $\mathrm{n}=5$ ). (G) HEK293T cells were transfected with eGFP-NLRP3 plasmid for $24 \mathrm{~h}$. Cells were pretreated with YDZG $(20 \mu \mathrm{M})$ for $1 \mathrm{~h}$ before being stimulated with LPS $\left(1 \mu \mathrm{g} \cdot \mathrm{mL}^{-1}\right)$ for another $6 \mathrm{~h}$, then treated with ATP $(5 \mathrm{mM})$ for $30 \mathrm{~min}(\mathrm{n}=3)$. Cells were fixed and stained with Hoechst $33342(1 \mu \mathrm{M})$ for imaging (scale bar $=20 \mu \mathrm{m}$ ). 
A

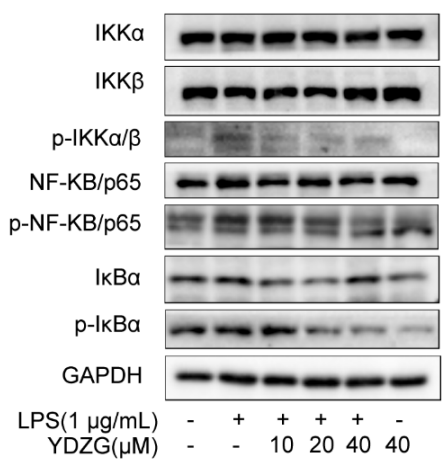

B

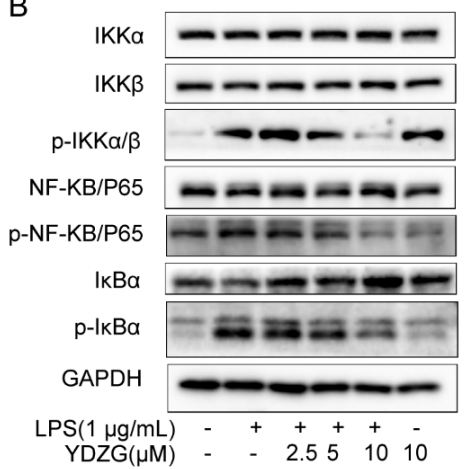

C

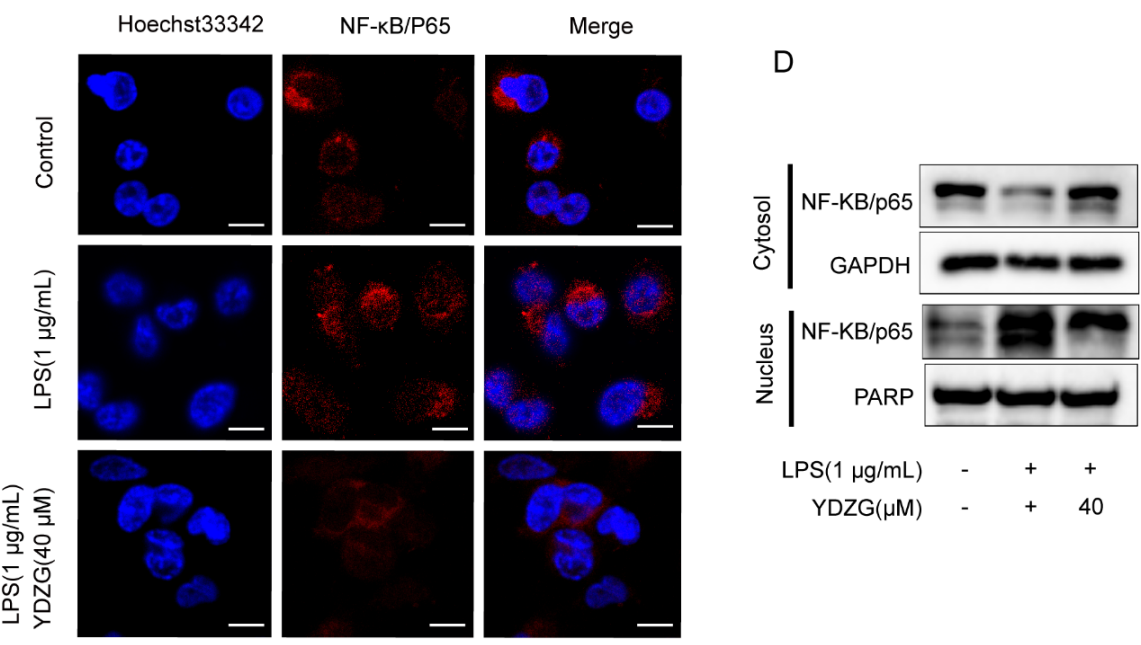

$\Phi$ were pretreated with the indicated concentrations of YDZG for $1 \mathrm{~h}$ before being stimulated with LPS (1 $\mu \mathrm{g} \cdot \mathrm{mL}^{-1}$ ) for another $2 \mathrm{~h}$. The expression of IKK- $\alpha$, IKK- $\beta$, p- IKK- $\alpha / \beta, \mathrm{I} \varkappa \mathrm{B}-\alpha$, p- I $\chi \mathrm{B}-\alpha, \mathrm{NF}-\varkappa \mathrm{B} / \mathrm{p} 65$, and p- NF- $\chi \mathrm{B} / \mathrm{p} 65$ proteins was determined by Western blotting $(\mathrm{n}=5)$. (C)THP-1 cells were pretreated with the indicated concentrations of YDZG for $1 \mathrm{~h}$ before being stimulated with LPS for another $2 \mathrm{~h}$. p65 translocation was determined using the immunofluorescence assay described in the Methods section ( $\mathrm{n}=$ 3). Primary antibody anti-NF- $x \mathrm{~B} / \mathrm{p} 65$ (1:100) and secondary antibody goat anti-Rabbit Alexa Fluor 568 (1:200) were employed (scale bar $=10 \mu \mathrm{m})$. (D) THP-1 cells were pretreated with YDZG $(4 \mu \mathrm{M})$ for $1 \mathrm{~h}$ and then stimulated with LPS $\left(1 \mu \mathrm{g} \cdot \mathrm{mL}^{-1}\right)$ for $1 \mathrm{~h}$. The localization of p65 in the cytoplasm and nucleus was detected by Western blotting $(\mathrm{n}=5)$. 

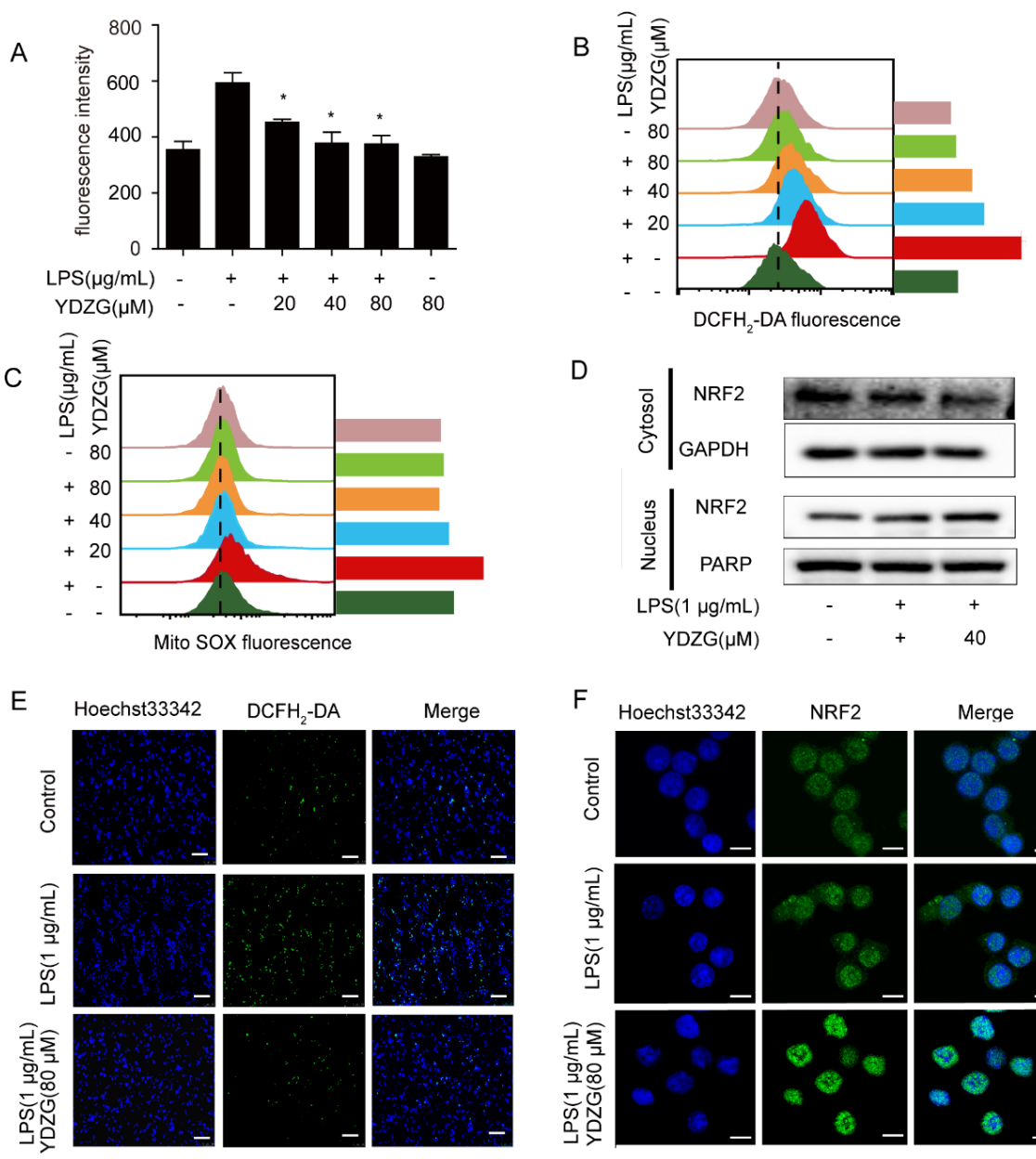

D
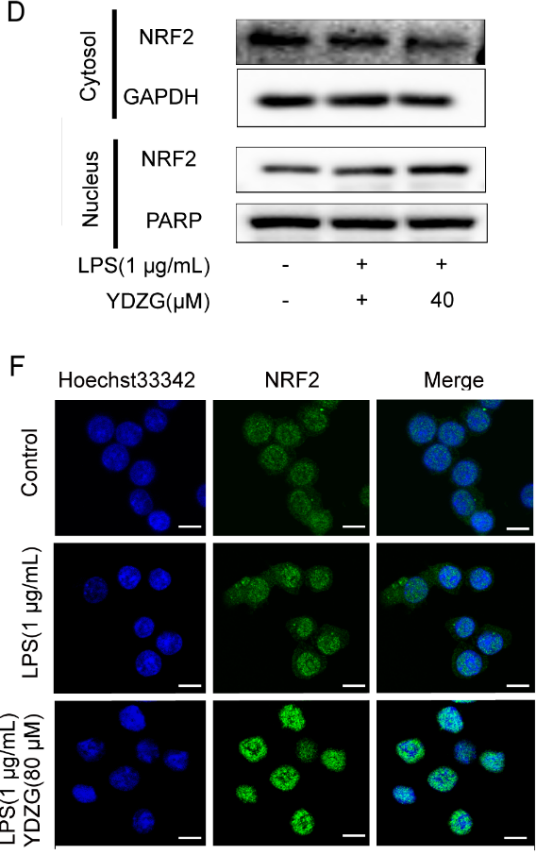

Figure 4 YDZG promote Nrf2 translocation from the cytoplasm into the nucleus and inhibited ROS generation. (A) RAW264.7 cells pretreated with YDZG (20,40, $80 \mu \mathrm{M})$ for $1 \mathrm{~h}$ were stimulated with LPS $(1 \mu \mathrm{g} / \mathrm{ml})$ for $8 \mathrm{~h}$. The ROS level was determined by a ROS kit (Sigma MAK143) according to the manufacturer's instructions $(\mathrm{n}=6)$. (B) RAW264.7 cells treated with for YDZG $(20,40,80 \mu \mathrm{M})$ for $1 \mathrm{~h}$ were incubated with LPS for $8 \mathrm{~h}$. Cells were stained with DCFH2-DA $(1 \mu \mathrm{M})$ for $30 \mathrm{~min}$. The fluorescence intensity was determined by flow cytometry $(\mathrm{n}=5)$. (C) RAW264.7 cells treated with for YDZG (20, 40, $80 \mu \mathrm{M})$ for $1 \mathrm{~h}$ were incubated with LPS for $8 \mathrm{~h}$. Cells were stained with MitoSOX Red mitochondrial superoxide indicator $(10 \mu \mathrm{M})$ for $30 \mathrm{~min}$. The fluorescence intensity was determined by flow cytometry $(\mathrm{n}=5)$. (D) RAW264.7 cells treated with for YDZG for $2 \mathrm{~h}$ were co-cultured with LPS for $2 \mathrm{~h}$. The protein expression of Nrf2 in cytoplasm and nucleus were detected by Western blotting $(n=5)$. (E) ROS level in cells was stained with DCFH2-DA $(10 \mu \mathrm{M})$. The images were captured by fluorescence microscopy (scale bar $=100 \mu \mathrm{m})$. (F) RAW264.7 cells were pretreated with YDZG $(80 \mu \mathrm{M})$ for $1 \mathrm{~h}$ before stimulated with LPS for another $2 \mathrm{~h}$. Nrf2 translocation was determined using the immunofluorescence assay described in the Methods section $(\mathrm{n}=3)$. Primary antibody anti-Nrf2 (1:100) and secondary antibody goat anti-Rabbit Alexa Fluor $488(1: 200)$ were employed (scale bar $=10 \mu \mathrm{m})$. Data are reported as mean \pm SEM; ${ }^{*} \mathrm{P}<0.05$ compared with the LPS alone group. 
A

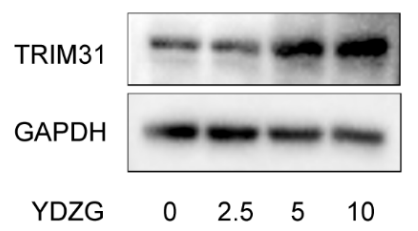

C

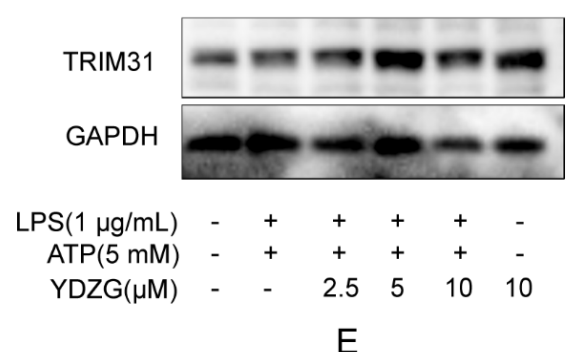

$\mathrm{E}$
B

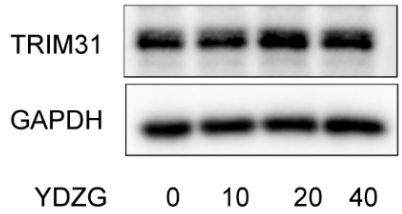

D

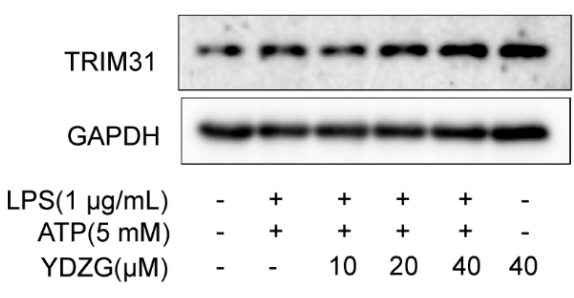

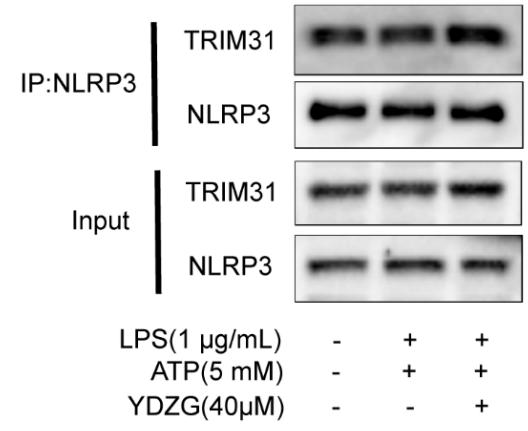

Figure 5 YDZG enhances TRIM31 expression. J774A.1 (A) and THP-1 (C) cells were pretreated with the indicated concentrations of YDZG for $6 \mathrm{~h}$. TRIM31 expression was examined by Western blotting $(\mathrm{n}=5)$. J774A.1 (B) or THP-1 (D) cells were pretreated with $10 \mu \mathrm{M}$ YDZG or $1 \mathrm{~h}$ before being stimulated with LPS $\left(1 \mu \mathrm{g} \cdot \mathrm{mL}^{-1}\right)$ for another $6 \mathrm{~h}$, and were then treated with ATP $(5 \mathrm{mM})$ for $30 \mathrm{~min}$ before harvesting. TRIM31 expression was examined by Western blotting $(\mathrm{n}=5)$. (E) THP-1 cells were pretreated with YDZG at $40 \mu \mathrm{M}$ for $1 \mathrm{~h}$ before being stimulated with LPS $\left(1 \mu \mathrm{g} \cdot \mathrm{mL}^{-1}\right)$ for another $6 \mathrm{~h}$, and were then treated with ATP $(5$ $\mathrm{mM}$ ) for $30 \mathrm{~min}$ before harvesting. Proteins were isolated and immunoprecipitated with an antibody against NLRP3 $(\mathrm{n}=5)$. 
A
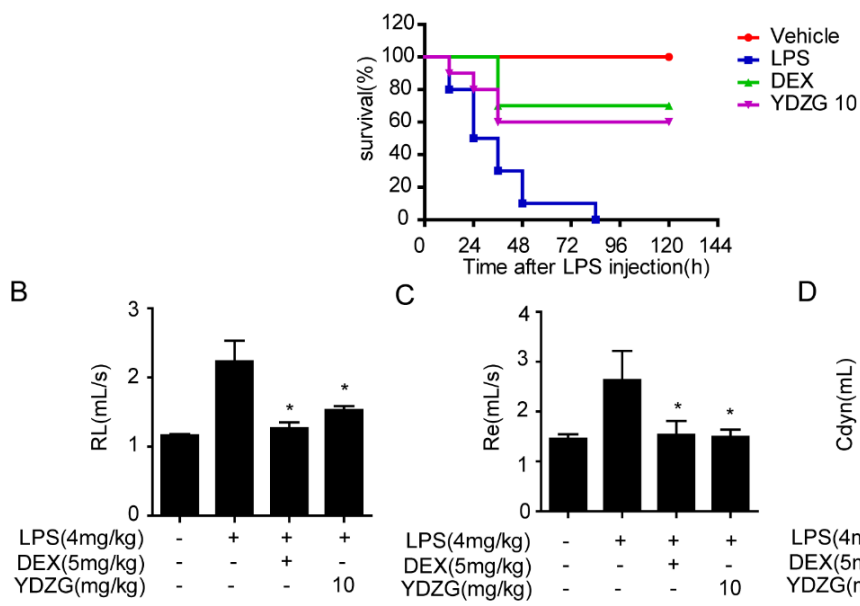

C
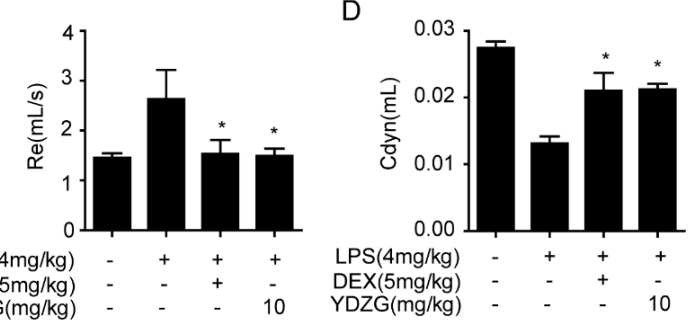

E

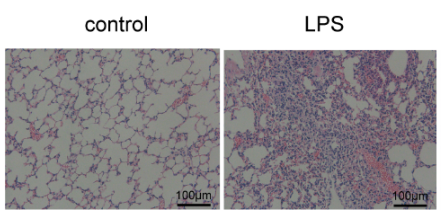

LPS+DEX

LPS+YDZG 5

LPS+YDZG10

Figure 6 YDZG ameliorates LPS-induced acute lung injury in mice. (A) Twenty mice per group were pretreated with vehicle or YDZG $\left(10 \mathrm{mg} \cdot \mathrm{kg}^{-1}\right.$, i.v.) for $2 \mathrm{~h}$ before a lethal dose of LPS $\left(15 \mathrm{mg} \cdot \mathrm{kg}^{-1}\right.$, i.t.) injection. DEX (5 mg. $\mathrm{kg}^{-1}$, i.p.) was used as a positive control. The survival rates of these mice were observed for the next $120 \mathrm{~h}$. Mice were treated with LPS and YDZG as described in the Material and Methods section. (B) Resistance of lung (RL), resistance of expiration (Re) and respiratory lung compliance (Cdyn) were detected using an AniRes2005 lung function test system (n=8). (C) Lung histopathology at 24 $\mathrm{h}$ after LPS challenge $(\mathrm{n}=8)$. Data are reported as mean $\pm \mathrm{SEM} ;{ }^{*} \mathrm{P}<0.05$ compared with the LPS alone group. 

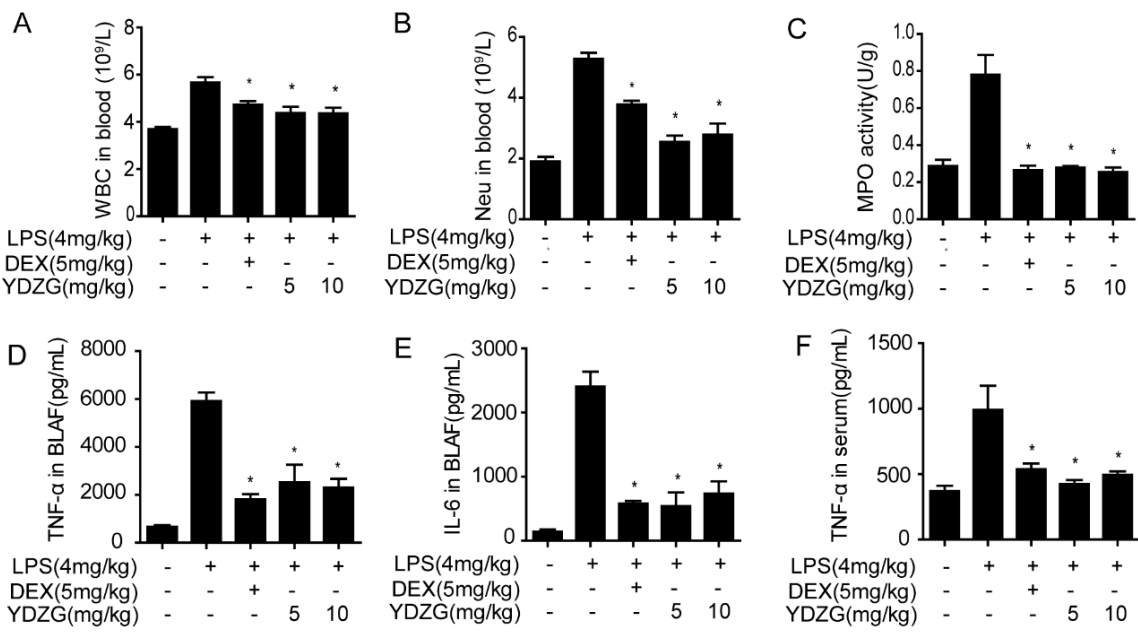

$\mathrm{E}$
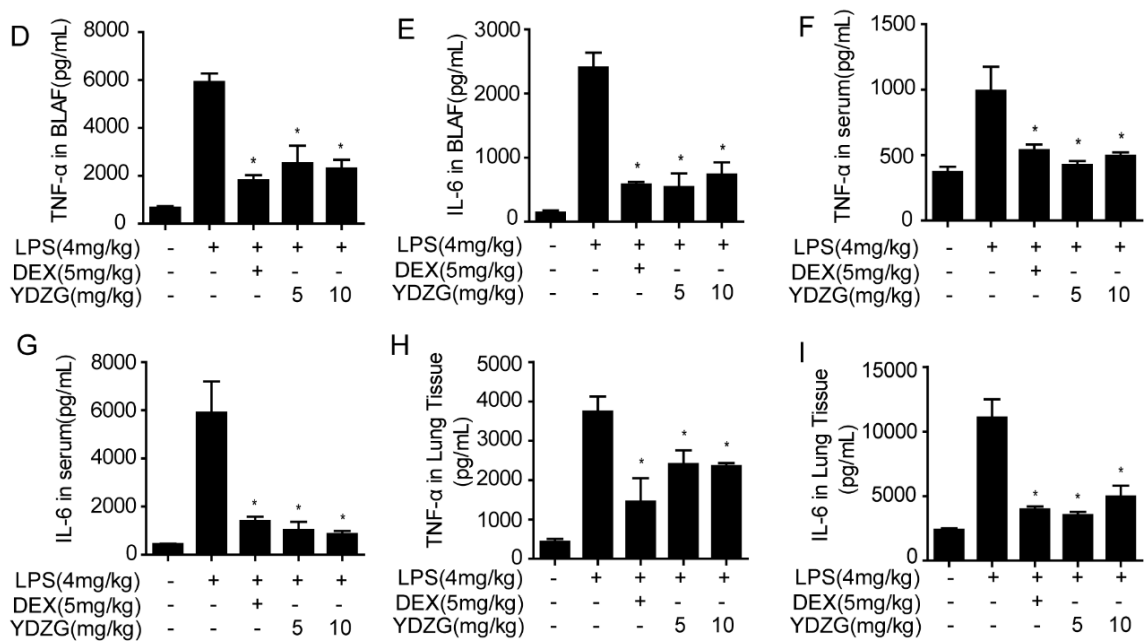

Figure 7 YDZG reduces LPS-induced infiltration of inflammatory cells and cytokine levels. Mice were treated with LPS and YDZG as described in the Materials and Methods section. YDZG reduced the number of (A) White blood cells and (B) neutrophils in blood following LPS challenge, which were determined using an auto hematology analyzer. Inflammatory cytokines, such as TNF- $\alpha$ and IL-6 in BALF $(\mathrm{D}, \mathrm{E})$, serum $(\mathrm{F}, \mathrm{G})$ and lung tissue $(\mathrm{H}, \mathrm{I})$ were determined using ELISA kits. Data are reported as mean \pm SEM; ${ }^{*} P<0.05$ compared with the LPS alone group $(\mathrm{n}=8)$. 


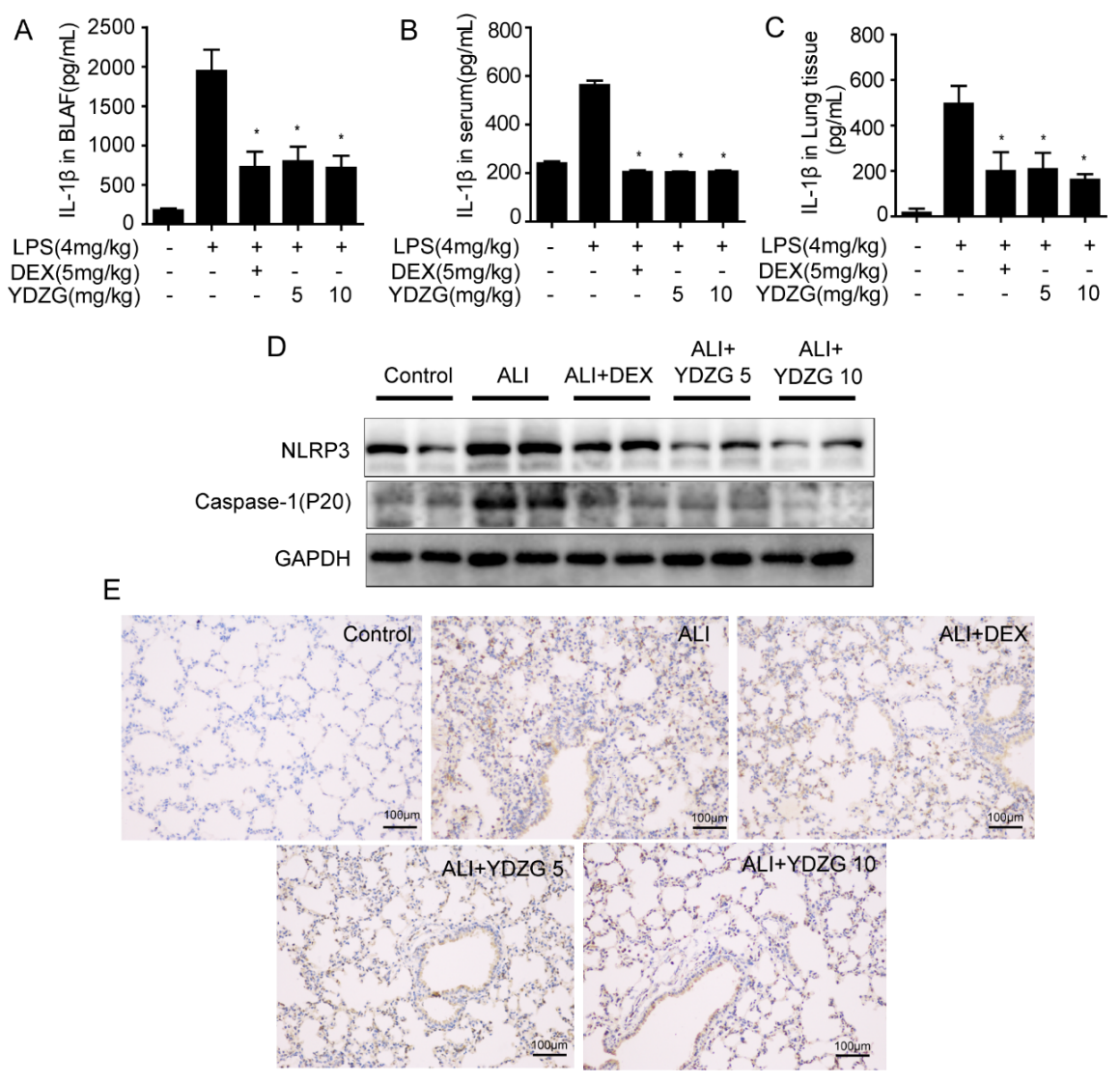

Figure 8 YDZG inhibits NLRP3 inflammasome activation in lung tissue. Mice were treated with LPS and YDZG as described in the Materials and Methods section. IL-1 $\beta$ in BALF (A), serum (B) and lung tissue $(\mathrm{C})$ were determined using ELISA kits. (D) The expression of NLRP3 and caspase-1 p20 proteins was determined by Western blotting $(n=5)$. (E) Immunohistochemical staining for NLRP3 in the lung tissues of mice challenged with LPS. Immunoreactivity is shown in brown (scale bar $=100 \mu \mathrm{m}$ ). Data are reported as mean \pm SEM; $\mathrm{n}=8 ;^{*} P<0.05$ compared with the LPS alone group. 


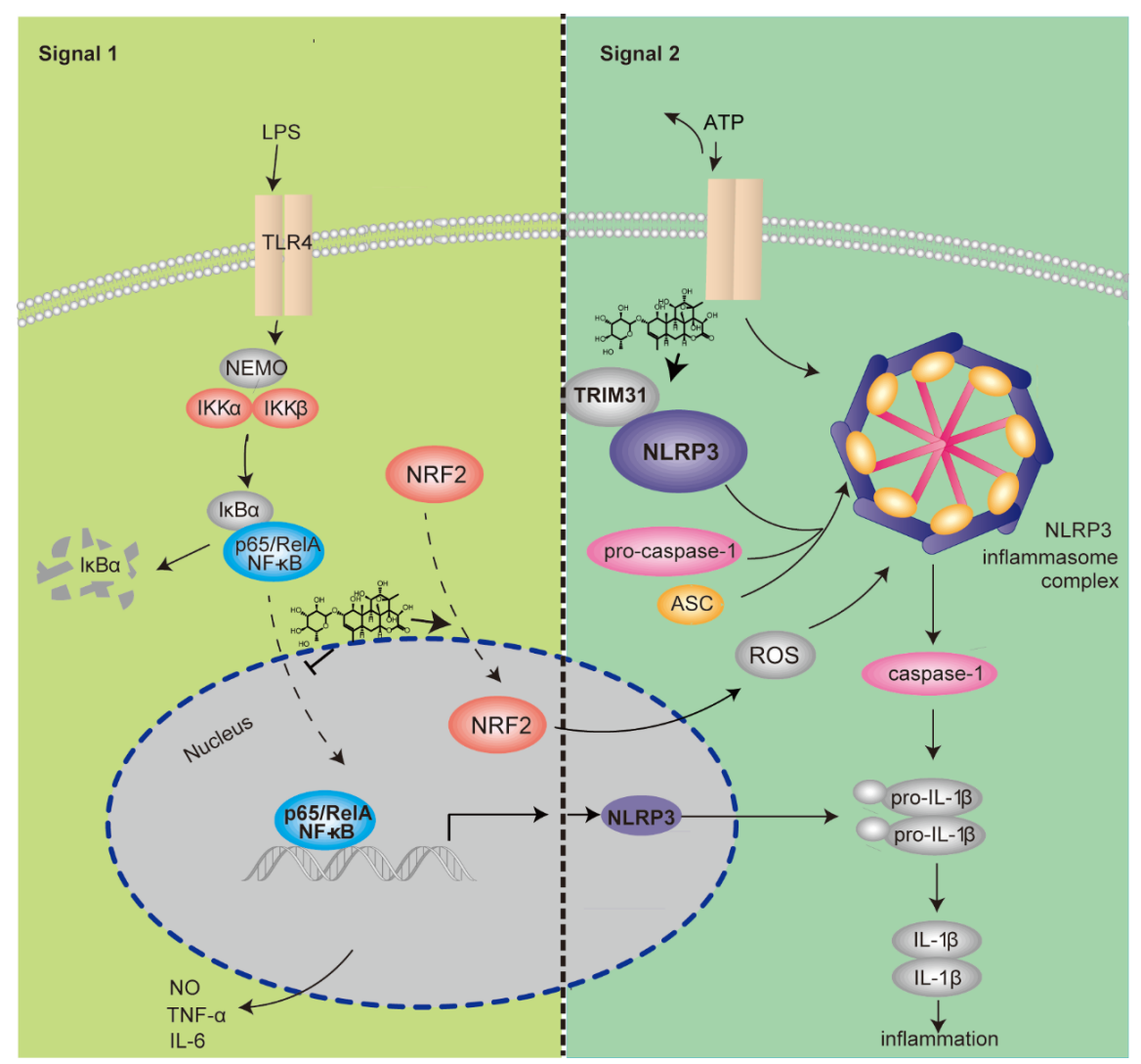

Figure 9 Working model for YDZG-based inhibition of NLRP3 inflammasome activation. Firstly, YDZG inhibits LPS-induced NF- $x \mathrm{~B}$ activation and disrupts NF- $x \mathrm{~B}$ nuclear translocation to inhibit NLRP3 expression. Secondly, YDZG promote Nrf2 translocation from the cytoplasm into the nucleus and inhibited ROS generation. Finally, YDZG enhances TRIM31 expression and promote formation of TRIM31-NLRP3 complexes. 